\title{
Structural and functional characteristics of cGMP- dependent methionine oxidation in Arabidopsis thaliana proteins
}

\author{
Claudius Marondedze ${ }^{1}$, Ilona Turek ${ }^{1}$, Brian Parrott ${ }^{1}$, Ludivine Thomas' ${ }^{1}$ Boris Jankovic ${ }^{2}$, Kathryn S Lilley ${ }^{3}$ \\ and Chris Gehring ${ }^{1 *}$
}

\begin{abstract}
Background: Increasing structural and biochemical evidence suggests that post-translational methionine oxidation of proteins is not just a result of cellular damage but may provide the cell with information on the cellular oxidative status. In addition, oxidation of methionine residues in key regulatory proteins, such as calmodulin, does influence cellular homeostasis. Previous findings also indicate that oxidation of methionine residues in signaling molecules may have a role in stress responses since these specific structural modifications can in turn change biological activities of proteins.
\end{abstract}

Findings: Here we use tandem mass spectrometry-based proteomics to show that treatment of Arabidopsis thaliana cells with a non-oxidative signaling molecule, the cell-permeant second messenger analogue, 8-bromo-3,5-cyclic guanosine monophosphate (8-Br-cGMP), results in a time-dependent increase in the content of oxidised methionine residues. Interestingly, the group of proteins affected by cGMP-dependent methionine oxidation is functionally enriched for stress response proteins. Furthermore, we also noted distinct signatures in the frequency of amino acids flanking oxidised and un-oxidised methionine residues on both the $\mathrm{C}$ - and $\mathrm{N}$-terminus.

Conclusions: Given both a structural and functional bias in methionine oxidation events in response to a signaling molecule, we propose that these are indicative of a specific role of such post-translational modifications in the direct or indirect regulation of cellular responses. The mechanisms that determine the specificity of the modifications remain to be elucidated.

Keywords: Methionine oxidation, Reactive oxygen species, 3,5-cyclic guanosine monophosphate, Tandem mass spectrometry-based proteomics, Arabidopsis thaliana

\section{Findings}

The debate of whether methionine (Met) oxidation of proteins is a purely chemical consequence of cellular oxidative damage or a protective mechanism against oxidative damage, or indeed a post-translational modification that can act as a specific cellular signal and/or response, is ongoing [1-3]. To shed light on this question we treated Arabidopsis suspension culture cells with the cell permeant second messenger analogue 8-bromo 3,5cyclic guanosine monophosphate (8-Br-cGMP). Cyclic

\footnotetext{
* Correspondence: Christoph.Gehring@KAUST.edu.sa

${ }^{1}$ Division of Chemical and Life Sciences and Engineering, King Abdullah University of Science and Technology, Thuwal 23955-6900, Saudi Arabia Full list of author information is available at the end of the article
}

GMP has a signaling role in many plant responses, including responses to light [4], hormones [5-8], signaling peptides [9], salt and drought stress [10,11], ozone, and defence responses [12-14]. Given that cGMP is not an oxidising agent and does not induce protein Met oxidation in vitro (Additional file 1), we tested if cGMP causes protein oxidation in vivo. To this end we used an OxiSelect ${ }^{\mathrm{TM}}$ Intracellular ROS Assay Kit (Cell Biolabs, Inc.) and show that cGMP can cause protein oxidation (Figure 1). We therefore conclude that any protein Met oxidation event resulting from cGMP treatment is most likely the result of direct or indirect cellular processes. To further characterise cGMP-dependent Met oxidation in vivo, a proteomic analysis was performed on A. thaliana (ecotype Col-0) cell

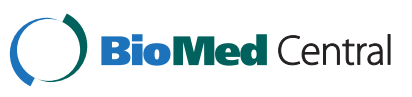




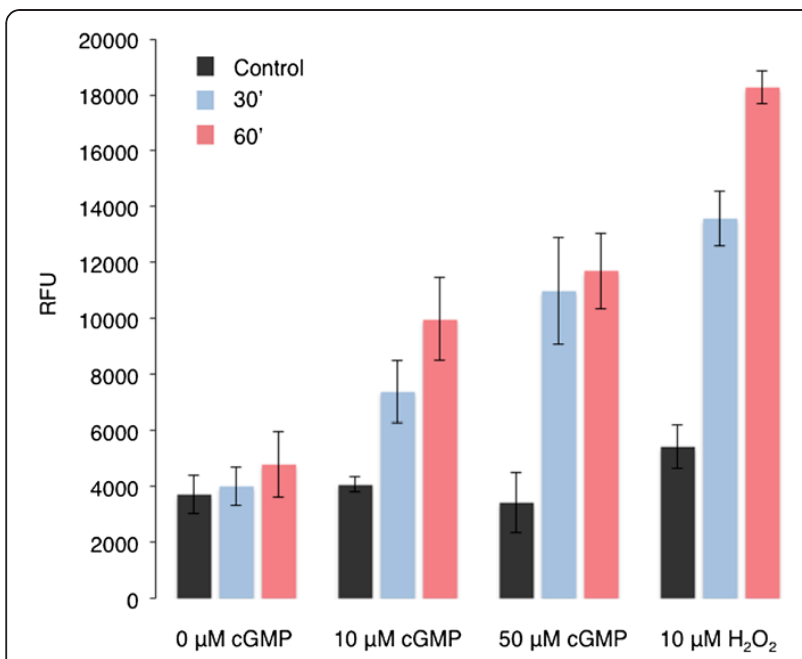

Figure 1 Protein oxidation assay. OxiSelect ${ }^{\mathrm{TM}}$ Intracellular ROS assay kit (Cell Biolabs, Inc. San Diego, CA) was used in the in vivo oxidation experiments according to the assay protocol provided by the manufacturer. Cultured Arabidopsis (Col-0) cells were placed in a black bottom 96-well cell culture plate for $2 \mathrm{~h}$ in a shaking incubator. The $2^{\prime}, 7^{\prime}$-dichlorofluorescein diacetate/media solution was added to the cells prior to incubation at $37^{\circ} \mathrm{C}$ for $1 \mathrm{~h}$. The dye-loaded cells were then treated with $10 \mu \mathrm{M}$ or $50 \mu \mathrm{M}$ of cGMP or $\mathrm{H}_{2} \mathrm{O}_{2}$. Fluorescence in the cells was measured at 30 and $60 \mathrm{~min}$ post-treatment at 480/530 nm using a PHERAstar FS microplate reader (BMG Labtech $\mathrm{GmbH}$, Germany) and the values plotted. Each bar represents data from 3 biological replicates $(n=3)$, the bars are the standard errors. Treatment with $8-B r-c G M P$ at the final concentration of $50 \mu \mathrm{M}$ induces statistically significant differences of the means at $p=0.05$ using a two-sample $t$-test.

suspension culture grown in Murashige and Skoog medium [15] following treatment with 8-Br-cGMP at the final concentration of $10 \mu \mathrm{M}$. Three biological replicate samples were collected at 0,30 and 60 minutes post-treatment. Total soluble proteins were extracted [16] and processed for tandem mass spectrometric identification of peptides containing oxidised Met residues (for methods see legend to Figure 2). Since our experimental protocol included a $\mathrm{TiO}_{2}$ enrichment step, usually applied for enrichment of phosphopeptides, we also tested to what extent peptides containing oxidized Met residues are enriched in samples subjected to the $\mathrm{TiO}_{2}$-based enrichment step either in the presence of absence of DHB (2,5-dihydroxybenzoic acid). In both cases the enrichment led to significant increase in ratio of spectra assigned to oxidised Met peptides to all assigned spectra (Table 1). Moreover, the presence of $\mathrm{DHB}$ in the $\mathrm{TiO}_{2}$-based enrichment step enhanced further increase in the number of oxidized peptides identified as compared to oxidized Met peptides enriched in the absence of DHB. This is consistent with a report that shows that Met oxidised peptides co-enrich with phosphopeptides because the affinity for the $\mathrm{TiO}_{2}$ (in the presence of $\mathrm{DHB}$ ) is stronger in oxidised as compared to non-oxidised isoforms [17].
In our proteomic analysis we considered a peptide as containing oxidised Met residue when it was identified with high confidence $(\geq 95 \%)$ in at least two biological replicates. A total of 385 cGMP-dependent methionine oxidised proteins were identified (Additional file 2, tab "AF1"). Assigned spectral counts (Additional file 2, tab "AF2") were used to estimate the relative ratio of peptides containing oxidized Met residue(s) as compared to total number of peptides identified in the sample.

An example of a tandem mass spectrometry result demonstrating oxidative modification of $\mathrm{TiO}_{2}$-enriched peptides extracted from 8-Br-cGMP-treated cells is shown in Figure 2. Peptides containing single oxidised Met residue show an increase in mass to charge $(\mathrm{m} / \mathrm{z})$ ratio of 15.9994 that corresponds to the average mass of an oxygen atom. For example, the peptide fragment (DHDKPIQQVIAEMTDGGVDR) of the alcohol dehydrogenase 1 (AT1G77120) in non-oxidised form has the $m / z$ ratio of 850.3723 (Figure 2A), while after oxidation of Met residue, the $\mathrm{m} / \mathrm{z}$ ratio shifts to 866.3673 (Figure 2B).

Further, we identified peptides with oxidised Met that occurred in all three biological replicates at different time points. We noted an increase in the total number of peptides containing residues of oxidised Met after cGMP treatment from 221 to 633 and then 1451 at 0,30 and 60 minutes, respectively (Figure $3 \mathrm{~A}$ and Additional file 2, tab "AF2"). These numbers represent 1.4\%, 19.4\% and $13 \%$, respectively, of the total number of peptides identified at each time point. Thus, the percentage of Met oxidised peptides identified is the highest at $30 \mathrm{~min}$ utes. In addition, the numbers of oxidised Met peptides detected at each time-point suggest that the total number of oxidised Met residues increased nearly 3-fold during the first 30 minutes of treatment and 7-fold after 60 minutes of treatment (Additional file 2, tab "AF2"). Of these redundant peptide fragments containing oxidized Met, 14 at 0 minutes, 113 at 30 minutes and 288 at 60 minutes were unique for each time-point. The total Met oxidised peptides correspond to 34 (at 0'), 136 (at 30') and 281 (at 60') Arabidopsis proteins, from which 10, 94, and 224 identified oxidized Met proteins are unique for each time-point, respectively (Figure 3B). This finding implies either that cGMP-dependent Met modifications are reversible and/or that some of the modified proteins have undergone proteolysis.

Gene ontology (GO) analysis (Fatigo ${ }^{+}$; http://babelomics3. bioinfo.cipf.es/) [18] of the unique proteins containing oxidised Met residues was undertaken. The result shows a significant enrichment of GO terms (adjusted p-value < $1.00 \mathrm{e}^{-02}$ ) in categories including 'response to stress', 'response to abiotic stimuli', 'response to oxidative stress', and 'response to oxygen and ROS metabolic process' (see Additional file 2, tab "AF3"). Moreover, the gene number in these GO 

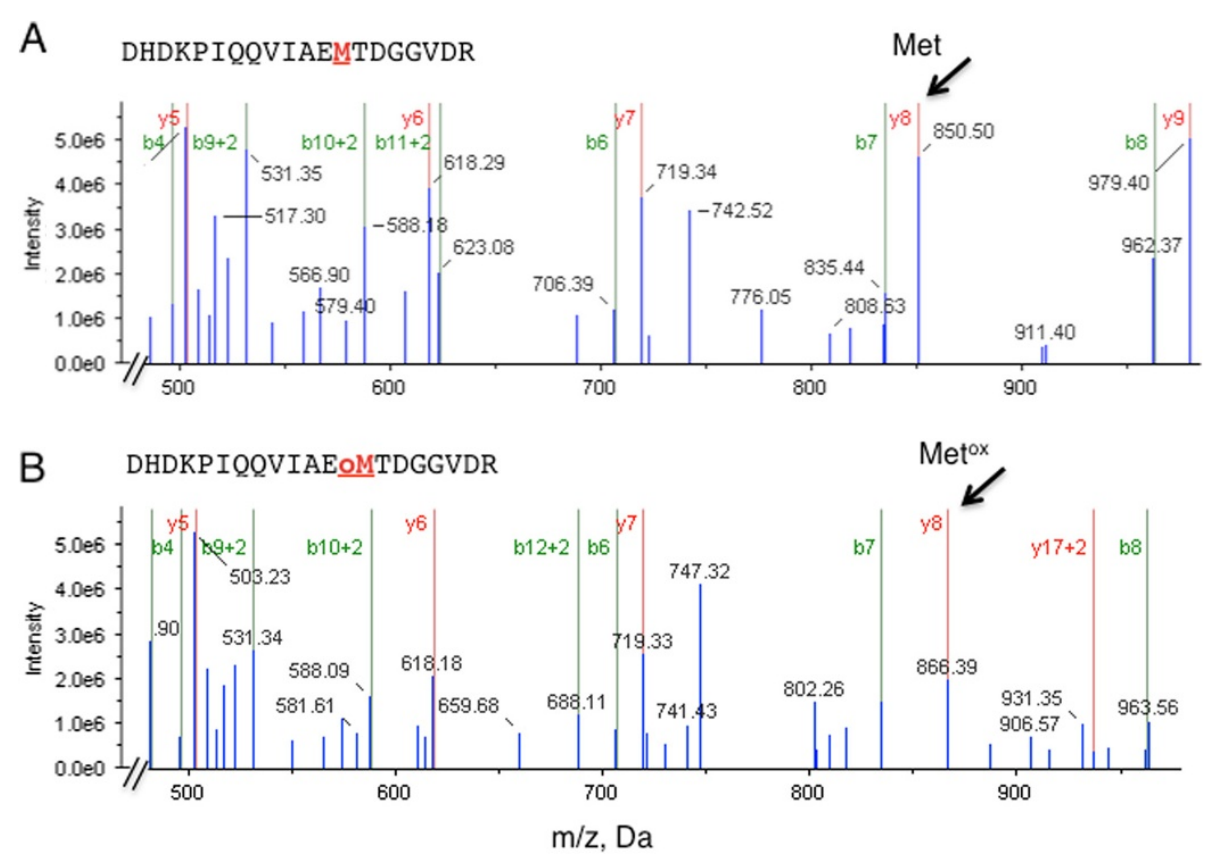

Figure 2 MS/MS spectra of ADH1 containing non-oxidised (A) and oxidised (B) methionine residues. Three biological replicates of $10 \mu \mathrm{M}$ 8-Br-cGMP-treated cells and $\mathrm{H}_{2} \mathrm{O}$ mock treated controls were collected at 0, 30 and 60 min. Proteins were precipitated using 10\% (w/v) trichloroacetic acid in acetone, re-solubilised in $7 \mathrm{M}$ urea, $2 \mathrm{M}$ thiourea and $4 \%(\mathrm{~W} / \mathrm{V})$ CHAPS, reduced, alkylated and trypsin digested. Peptides were fractionated by cation exchange chromatography. Methionine oxidised peptides were enriched using $\mathrm{TiO}_{2}$ beads and re-suspended in $5 \%$ $(\mathrm{v} / \mathrm{V})$ acetonitrile and $0.1 \%(\mathrm{v} / \mathrm{v})$ formic acid prior to identification and quantitation by LTQ Orbitrap coupled with a nanoelectrospray ion source. Peptides $(5 \mu \mathrm{L}$ ) were injected onto a $50 \mathrm{~mm} \times 0.3 \mathrm{~mm}$ Magic C18AQ column. The top 10 precursor ions were selected with a resolution of 60,000 for fragmentation using normalized collision-induced dissociation set at 35.0. Spectra were searched against TAIR using MASCOT, with a precursor mass tolerance of $10 \mathrm{ppm}$, a fragment ion mass tolerance of $0.3 \mathrm{Da}$, one missed cleavage, carbamidomethyl cysteine residues as fixed modification and oxidation and dioxidation of methionine residues as variable modifications. Proteins with a score $>95 \%$ were considered positively identified (corresponding score $\leq 31$ ). Spectra were further processed with the Scaffold ${ }^{\mathrm{TM}}$ software using the "Trans-Proteomic Pipeline" algorithm (threshold 95\%). Oxidised Met residues showed an increase in mass/charge ratio (m/z) of 15.9994. Arrows show Met residues at position 13 in the fragment DHDKPIQQVIAEMTDGGVDR of AT1G77120 before oxidation ( $\mathrm{m} / \mathrm{z}$ ratio 850.3723) (A) and after oxidation $(\mathrm{m} / \mathrm{z}$ ratio 866.3673) (B).

categories also increased over time (Figure 4). It therefore appears that the application of a membrane-permeable analogue of the second messenger cGMP induces Met oxidation in a set of proteins that are over-represented in specific functional groups.

Proteins enriched in the GO categories: 'response to oxidative stress', 'response to ROS', 'response to oxygen', and 'ROS metabolic process' showed four main patterns. (1) Loss of peptides or proteins containing oxidised Met residue(s) and reduction in the number of peptide copies after treatment, e.g. glyceraldehyde-3-phosphate dehydrogenase (AT1G13340; AT3G04120) and 60S acidic ribo- somal protein (AT2G27720). Loss of Met oxidised peptides can occur due to degradation of copies of proteins with oxidised Met residues or the reduction of oxidised Met residues. (2) Increase in the number of oxidised peptide fragments after treatment, e.g. peroxidase (AT2G22420; AT4G08770). This may imply that cGMP either indirectly induces over-expression of specific proteins with peptide fragments susceptible to oxidation or preferentially induces oxidation of Met residues in specific proteins without necessarily inducing transcription and/or translation. (3) New peptides detected with Met residues oxidised after treatment, e.g. ATP synthase (AT5G08670),

Table $1^{\dagger}$ Enrichment of methionine oxidized peptides (oxMet) using $\mathrm{TiO}_{2}$ with and without DHB

\begin{tabular}{|c|c|c|c|c|c|c|c|c|c|c|c|c|}
\hline & \multicolumn{4}{|c|}{ Without enrichment } & \multicolumn{4}{|c|}{$\mathrm{TiO}_{2}$ enrichment without $\mathrm{DHB}$} & \multicolumn{4}{|c|}{$\mathrm{TiO}_{2}$ enrichment with $\mathrm{DHB}$} \\
\hline & R1 & R2 & R3 & R4 & R1 & R2 & R3 & R4 & R1 & R2 & R3 & R4 \\
\hline Assigned spectra & 123109 & 67688 & 42897 & 89362 & 38403 & 56545 & 14450 & 4288 & 28092 & 11880 & 8567 & 3812 \\
\hline Assigned spectra oxMet pep. & 3073 & 288 & 49 & 3930 & 15803 & 4273 & 6303 & 424 & 26913 & 4370 & 6586 & 1318 \\
\hline \% oxMet & 2.5 & 0.4 & 0.1 & 4.4 & 41.2 & 7.6 & 43.6 & 9.9 & 95.8 & 36.8 & 76.9 & 34.6 \\
\hline
\end{tabular}

${ }^{\dagger}$ The cell suspension culture was treated with $10 \mu \mathrm{M} \mathrm{H}_{2} \mathrm{O}_{2}$ for 30 minutes. The experimental procedures are as described in the legend to Figure 2 . 


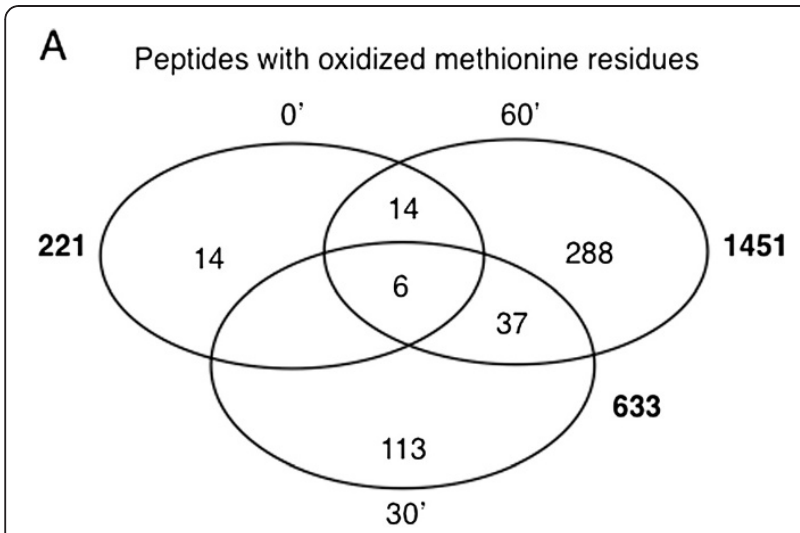

B Proteins with oxidized methionine residues

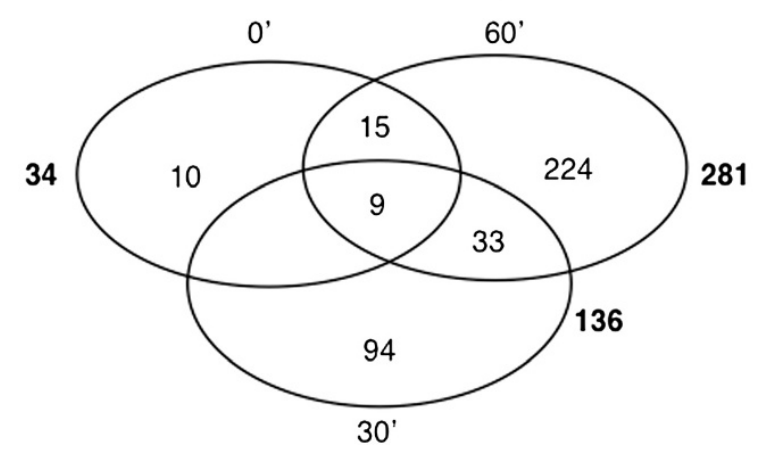

Figure 3 Quantitative representation of peptides $(A)$ and proteins (B) containing oxidised Met residues identified by mass spectrometry. The total numbers of peptides and proteins containing at least one oxidised Met residue identified by LC-MS/MS in protein samples extracted from $A$. thaliana cells treated with $10 \mu \mathrm{M} 8-\mathrm{Br}$-cGMP and collected at 0,30 and 60 min post-treatment were analysed. Proteins matching the peptides were identified by searching against TAIR10 database using MASCOT and TPP algorithm, and only proteins within a 95\% confidence threshold were considered. The total number of peptides $(\mathbf{A})$ or proteins (B) are indicated outside the Venn diagram (in bold), the numbers inside are the unique peptides or proteins identified at each time point. Fourteen, 113 and 288 peptide fragments containing at least one oxidised Met appear only at either 0, 30 or $60 \mathrm{~min}$. This corresponds to an increase in the total number of time point specific Met oxidised proteins from 10 to 94 and then to 224 (B).

and (4) multiple Met residues becoming oxidised after treatment, e.g. in the heat shock protein 70 (AT3G12580) (Additional File 2, tab "AF1").

A total of 299 proteins (78\% of all unique proteins containing oxidised Met residues) comprised only one oxidised Met residue, while 86 proteins ( $22 \%$ of all unique proteins containing oxidised Met residues) had $\geq 2$ oxidised Met residues (Additional file 2, tab "AF4"). Of those multioxidised 86 proteins 10 proteins had $\geq 4$ Met residues oxidised (Additional file 2, tab "AF5"). The 'low expression of osmotically responsive gene 1' (AT1G56070), 'tubulin 9' (AT4G20890), 'heat shock protein 70' (AT5G02500) and 'male gametophyte defective 1' (AT2G21870) contain the largest number of oxidised residues, representing 16\%, 23\%, 29\% and 50\%, respectively, of their total Met content (Table 2 and Additional file 2, tab "AF5"). It is of interest that heat shock proteins AT5G02500, AT3G12580 and AT5G09590 each had at least four oxidised Met residues.

The protein with the highest number of Met oxidised peptide fragments in response to cGMP is the methylesterase PCR A (AT1G11580) with 235 oxidised fragments representing $\approx 30 \%$ of the identified peptides (Table 3 and Additional file 2, tab "AF5"). Among the proteins with peptides show the greatest extend of Met oxidation, peroxidase superfamily protein (AT2G22420) showed the highest ratio of Met oxidised peptides to all identified peptide fragments of the protein (114 out of 160), representing $\approx 70 \%$ of total peptides detected and assigned to this protein. Localised in the cytosol, this family of proteins is mainly involved in oxidation-reduction processes and responses to oxidative stress. In addition to ROS being generated by activation of a plasma membrane NADPH oxidase [19], an extracellular cell wall peroxidase is also involved in the biosynthesis of $\mathrm{H}_{2} \mathrm{O}_{2}$ [20] and plays an important role in plant resistance to pathogens [21]. A previous study using antisense expression of a French bean peroxidase cDNA in Arabidopsis showed a reduction in mRNA level of peroxidase (AT3G49120), which in turn led to a reduction in the oxidative burst and eventually a reduced resistance to fungal and bacterial pathogens [22]. The authors hypothesized that peroxidases have a role in sustaining and/or initiating ROS that signal early defence responses in plants. Given that peroxidases themselves are highly susceptible to Met oxidation, and that this modification limits their activity, it suggests a negative feedback mechanism and links Met oxidation to the control of cellular redox balance. It has also been reported that $\mathrm{O}_{3}$ and NO, both oxidising agents, induce transcriptional activation of scavenger-encoding genes, like alternative oxidase and glutathione peroxidase [12]. Furthermore, oxidation of Met residues has been shown to target both specific functional domains and consequently modify functional characteristics, e.g. in cytochrome c [23] and peroxidases [24], as well as regions outside functional domains, like in the nascent polypeptide-associated complex where modifications do not seem to affect functionality.

Given that Met oxidation can profoundly alter cellular responses, the question is if there is evidence for site selectivity and if so, what determines it. In order to address this question, we have subjected all 385 proteins with one or several oxidised Met to further analysis and noted the following. Firstly, the average Met frequency in the set of proteins containing oxidised Met is 0.027 as compared to the other amino acids (AA) in the complete proteome where it is 0.025 [25], and hence is nearly the same; we also noted that none of the 50 Arabidopsis proteins with the highest frequency of Met occurrence 


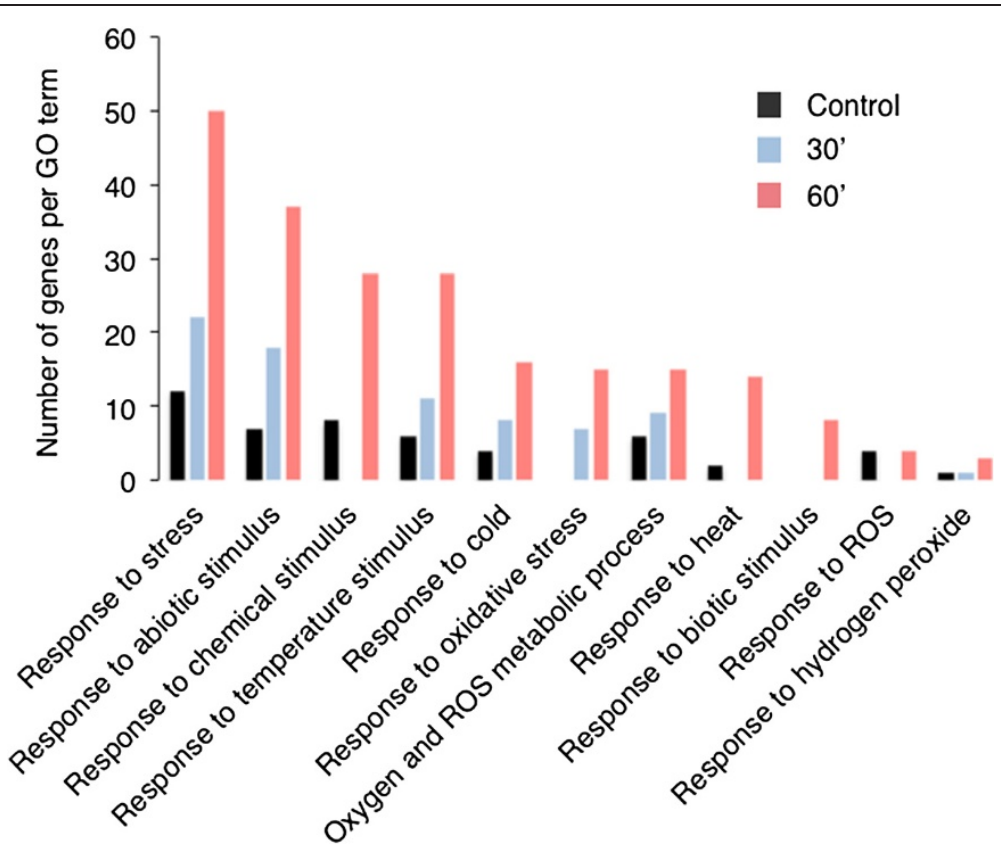

Figure 4 Enriched gene ontology (GO) terms (adjusted p-value $<1.00 \mathrm{e}^{-02}$ ). Unique proteins containing oxidised Met identified in cGMP-treated samples were used to search for GO term enrichment using Fatigo (http://babelomics3.bioinfo.cipf.es/) and selected significantly enriched terms are represented. A significant increase in the enrichment of GO terms over time was observed as well as an increase in the number of genes in these $\mathrm{GO}$ categories.

(0.09) contained any oxidised Met residues. This indicates that Met frequencies in proteins per se are not a factor that determines increased oxidation. Secondly, of the 385 proteins containing at least one modified Met residue, only eight residues were on the N-terminus, and of the 150 double Met (-MM-) residues, five proteins had both residues oxidised and eight proteins - only one. Thirdly, of the 575 oxidised Met residues detected, 75 had a glutamic acid (Glu) and 68 had an aspartic acid (Asp) as an immediate $\mathrm{C}$-terminal neighbour and this bias is likely, at least in part, due to preferential enrichment of these AAs by $\mathrm{TiO} 2$ [26], however we also find the uncharged alanine (Ala: 47) enriched on the C-terminus. The most frequent N-terminal neighbours are glutamic acid (Glu: 67) and again the uncharged alanine (Ala: 65). The least frequent $\mathrm{C}$ - and N-terminal neighbours are tryptophan (Trp: 2; 0 ,

Table 2 cGMP-dependent proteins with multiple methionine residues oxidised and their enriched GO terms

\begin{tabular}{|c|c|c|c|c|}
\hline Accession No. & Description & $\begin{array}{l}\text { *OxMet/total } \\
\text { Met residues }\end{array}$ & Annotations & $\begin{array}{l}\text { Enriched } \\
\text { GO term(s) }\end{array}$ \\
\hline AT1G56070 & Low expression of osmotically responsive gene 1 & $5 / 38$ & RC, translational elongation & RTS \\
\hline AT2G21870 & Male gametophyte defective 1 & $5 / 10$ & $\mathrm{Co}^{2+}, \mathrm{Cu}^{2+}$ and $\mathrm{Zn}^{2+}$ binding & \\
\hline AT4G20890 & Tubulin 9 & $5 / 22$ & GTP binding, GTP catabolic process, RCa & \\
\hline AT5G02500 & Heat shock protein 70 & $5 / 17$ & $\begin{array}{l}\text { Responses to heat, bacterium, } \mathrm{H}_{2} \mathrm{O}_{2} \text { and } \mathrm{HLI} \text {, } \\
\text { RCa, RTS, RV }\end{array}$ & RTS, RV \\
\hline AT3G12580 & Heat shock protein 70 & $4 / 16$ & $\begin{array}{l}\text { Responses to heat, bacteria, } \mathrm{H}_{2} \mathrm{O}_{2}, \mathrm{HLI}, \mathrm{RCa} \text {, } \\
\text { RTS, RV }\end{array}$ & RTS, RV \\
\hline AT3G27240 & Cytochrome C1 family & $4 / 8$ & Heme binding, $\mathrm{Fe}^{2+}$ binding & \\
\hline AT4G02930 & GTP binding elongation factor Tu family protein & $4 / 14$ & ATP, $\mathrm{CO}^{2+}$ and $\mathrm{Zn}^{2+}$ binding, $\mathrm{RCa}$ & \\
\hline AT1G24310 & Unknown protein & $4 / 12$ & & \\
\hline AT1G27390 & Translocase outer membrane 20 & $4 / 8$ & Metal ion binding & \\
\hline AT4G10480 & Nascent polypeptide-associated complex & $4 / 10$ & $\begin{array}{c}\text { Transcription regulation and mitochondrial } \\
\text { translocation }\end{array}$ & \\
\hline
\end{tabular}

HLI- high light intensity, RC- response to cold, RCa- response to cadmium ion, RTS- response to temperature stimulus (GO:0009266), RV- response to virus (GO:0009615), adjusted $\mathrm{p}<1.78 \mathrm{e}^{-2}$. $^{*}$ Ox- oxidised. 
Table 3 Highly methionine oxidised proteins after cGMP treatment

\begin{tabular}{|c|c|c|c|c|}
\hline $\begin{array}{l}\text { Accession } \\
\text { No. }\end{array}$ & Description & $\begin{array}{l}\% \text { of oxidised } \\
\text { fragments }\end{array}$ & Annotations & $\begin{array}{l}\text { Enriched GO } \\
\text { term(s) }\end{array}$ \\
\hline AT2G22420 & $\begin{array}{l}\text { Peroxidase superfamily } \\
\text { protein }\end{array}$ & 71.3 & Oxidation-reduction process, response to oxidative stress & \\
\hline AT5G12250 & $\beta-6$-tubulin & 62.6 & Response to salt stress, $\mathrm{RC}$ & \\
\hline AT4G10480 & NAC & 50.9 & Transcription regulation and mitochondrial translocation & \\
\hline AT3G15950 & NAI2 & 41.8 & Response to salt stress & \\
\hline AT2G05710 & Aconitase 3 & 35.0 & Response to ABA stimulus, oxidative and salt stress, RCa & \\
\hline AT5G02500 & Heat shock protein 70 & 33.6 & $\begin{array}{c}\text { Defense response to bacteria and fungus, response to heat, } \\
\text { and virus, } R C a, R C\end{array}$ & RAS, RS \\
\hline AT2G21660 & $\begin{array}{l}\text { Cold, circadian rhythm and } \\
\text { RNA binding } 2\end{array}$ & 32.7 & $\begin{array}{l}\text { Regulation of stomatal movement, response to osmotic and salt } \\
\text { stress, RCa, RC }\end{array}$ & RAS, RS \\
\hline AT1G11580 & Methylesterase PCR A & 30.8 & Metabolic process, negative regulation of catalytic activity & \\
\hline AT1G77120 & Alcohol dehydrogenase & 18.7 & $\begin{array}{l}\text { Cellular respiration, oxidation-reduction process, response to hypoxia, } \\
\qquad \text { osmotic stress and salt stress, RCa }\end{array}$ & RAS, RS \\
\hline AT1G53240 & $\begin{array}{l}\text { Mitochondrial malate } \\
\text { dehydrogenase }\end{array}$ & 16.9 & $\begin{array}{c}\text { Oxidation-reduction process, defense response to bacteria, response } \\
\text { to salt stress, } \mathrm{RCa}, \mathrm{RC}\end{array}$ & \\
\hline
\end{tabular}

NAC Nascent polypeptide-associated complex, NAI2- similar to TSK-associating protein 1, RC Response to cold, $R C a$ Response to cadmium ion, RAS Response to abiotic stimulus (GO:0009628), RS Response to stress (GO:0006950), adjusted $\mathrm{p}<4.15 \mathrm{e}^{-2}$.

respectively) and cysteine (Cys: $1 ; 2$, respectively). We further compared the observed frequency of amino acids flanking Met positions to their theoretically expected values implied from the analysis of overall $\mathrm{AA}$ frequencies in the entire Arabidopsis proteome [25]. This process involved counting all of the occurrences of AAs in the proteome and establishing their relative frequency in the proteome, and the analysis was done in Matlab (Version R2010b). We note that, while under-represented (i.e. the observed frequency in positions flanking Met is lower than their average in the entire proteome), leucine and serine are the most frequent flanking AAs. In turn, Met flanking a Met is $35 \%$ over-represented on the N-terminal side and $25 \%$ over-represented on the C-terminal side. In contrast, oxidised Mets have much reduced relative preference for Met ( $-14 \%$ on $\mathrm{N}$-terminus and $-44 \%$ on C-terminus), albeit based on a very limited sample. Other under-represented flanking AAs are cysteine (Cys) and proline (Pro).

The rapidly evolving field of redox proteomics provides new evidence supporting the notion that oxidation of Met residues may have a great impact on protein activity, regulation of biochemical pathways and cellular function in response to changing environmental conditions. This is consistent with the observed Met oxidation accumulation in plants under low temperature conditions and the fact that plant methionine sulfoxide reductase (MSR) confers increased tolerance to freezing [27]. It is also conceivable that the differential oxidation footprint of Met is a result of different susceptibility depending e.g. on the conformation of the protein or on differential access for repair of the MSR to different proteins or protein domains. Furthermore, our results are an indication that many of the Arabidopsis proteins involved in modulating the level of reactive oxygen species (ROS), including ROS-scavenging and ROS-producing proteins [19], may - at least in part be regulated by oxidation of their Met residues.

\section{Additional files}

Additional file 1: The file contains the list of methionine oxidised peptides and their assigned spectral counts following in vitro cGMP treatment experiment.

Additional file 2: The file contains the lists of all methionine oxidised proteins and fragments and the result of the gene ontology analysis.

\section{Competing interests}

The authors declare that they have no competing interests.

\section{Authors' contributions}

CG conceived the project. CM, IT, BP, LT and KSL designed and performed the experiments, BJ performed the bio-informatics analyses, and CG wrote the manuscript with critical input from all authors. All authors read and approved the final manuscript.

\section{Author details}

${ }^{1}$ Division of Chemical and Life Sciences and Engineering, King Abdullah University of Science and Technology, Thuwal 23955-6900, Saudi Arabia. ${ }^{2}$ Computational Bioscience Research Center, King Abdullah University of Science and Technology, Thuwal 23955-6900, Saudi Arabia. ${ }^{3}$ Cambridge Centre for Proteomics, Cambridge Systems Biology Centre, Department of Biochemistry, University of Cambridge, Tennis Court Road, Cambridge CB2 1QR, UK.

Received: 10 May 2012 Accepted: 29 December 2012

Published: 5 January 2013

\section{References}

1. Hoshi T, Heinemann S: Regulation of cell function by methionine oxidation and reduction. J Physiol 2001, 531:1-11.

2. Stadtman ER, Moskovitz J, Levine RL: Oxidation of methionine residues of proteins: biological consequences. Antiox Redox Sign 2003, 5:577-582.

3. Hardin SC, Larue CT, Oh MH, Jain V, Huber SC: Coupling oxidative signals to protein phosphorylation via methionine oxidation in Arabidopsis. Biochem J 2009, 422:305-312. 
4. Neuhaus G, Bowler C, Hiratsuka K, Yamagata H, Chua NH: Phytochromeregulated repression of gene expression requires calcium and cGMP. EMBO J 1997, 16:2554-2564.

5. Pharmawati M, Billington T, Gehring CA: Stomatal guard cell responses to kinetin and natriuretic peptides are cGMP-dependent. Cell Mol Life SCi 1998, 54:272-276.

6. Kwezi L, Meier S, Mungur L, Ruzvidzo O, Irving H, Gehring C: The Arabidopsis thaliana brassinosteroid receptor (AtBRI1) contains a domain that functions as a guanylyl cyclase in vitro. PLOS One 2007, 2:e449.

7. Kwezi L, Ruzvidzo O, Wheeler Jl, Govender K, lacuone S, Thompson PE, Gehring C, Irving HR: The phytosulfokine (PSK) receptor is capable of guanylate cyclase activity and enabling cyclic GMP-dependent signaling in plants. J Biol Chem 2011, 286:22580-22588.

8. Isner JC, Nuhse T, Maathuis FJ: The cyclic nucleotide CGMP is involved in plant hormone signalling and alters phosphorylation of Arabidopsis thaliana root proteins. J Exp Bot 2012, 63:3199-3205

9. Gehring CA, Irving HR: Natriuretic peptides - a class of heterologous molecules in plants. Int J Biochem Cell Biol 2003, 35:1318-1322.

10. Maathuis FJ, Sanders D: Sodium uptake in Arabidopsis roots is regulated by cyclic nucleotides. Plant Physio/ 2001, 127:1617-1625.

11. Donaldson L, Ludidi N, Knight MR, Gehring C, Denby K: Salt and osmotic stress cause rapid increases in Arabidopsis thaliana cGMP levels. FEBS Lett 2004, 569:317-320.

12. Pasqualini S, Meier S, Gehring C, Madeo L, Fornaciari M, Romano B, Ederli L Ozone and nitric oxide induce cGMP-dependent and -independent transcription of defence genes in tobacco. New Phytol 2009, 181:860-870.

13. Meier S, Madeo L, Ederli L, Donaldson L, Pasqualini S, Gehring C: Deciphering CGMP signatures and cGMP-dependent pathways in plant defence. Plant Sign Behav 2009, 4:307-309.

14. Qi Z, Verma R, Gehring C, Yamaguchi Y, Zhao YC, Ryan CA, Berkowitz GA $\mathrm{Ca}^{2+}$ signaling by plant Arabidopsis thaliana Pep peptides depends on AtPepR1, a receptor with guanylyl cyclase activity, and cGMP-activated $\mathrm{Ca}^{2+}$ channels. Proc natl Acad Sci USA 2010, 107:21193-21198.

15. Murashige T, Skoog F: A revised medium for rapid growth and bioassays with tobacco tissue cultures. Plant Physiol 1962, 15:473-497.

16. Garavaglia BS, Thomas L, Gottig N, Dunger G, Garofalo CG, Daurelio LD, Ndimba B, Orellano EG, Gehring C, Ottado J: A eukaryotic-acquired gene by a biotrophic phytopathogen allows prolonged survival on the host by counteracting the shut-down of plant photosynthesis. PLoS One 2010, 5:e8950.

17. Eriksson A, Bergquist J, Edwards K, Hagfeldt A, Malmstrom D, Agmo Hernandez V: Optimized protocol for on-target phosphopeptide enrichment prior to matrix-assisted laser desorption-ionization mass spectrometry using mesoporous titanium dioxide. Anal Chem 2010, 82:4577-4583.

18. Al-Shahrour F, Carbonell J, Minguez P, Goetz S, Conesa A, Tarraga J, Medina I, Alloza E, Montaner D, Dopazo J: Babelomics: advanced functional profiling of transcriptomics, proteomics and genomics experiments. Nucl Acids Res 2008, 36:W341-346.

19. Mittler R, Vanderauwera S, Gollery M, Van Breusegem F: Reactive oxygen gene network of plants. Trends Plant Sci 2004, 9:490-498.

20. Grant JJ, Loake GJ: Role of reactive oxygen intermediates and cognate redox signaling in disease resistance. Plant Physiol 2000, 124:21-29.

21. Bolwell GP, Bindschedler LV, Blee KA, Butt VS, Davies DR, Gardner SL, Gerrish C, Minibayeva F: The apoplastic oxidative burst in response to biotic stress in plants: a three-component system. J Exp Bot 2002, 53:1367-1376.

22. Bindschedler LV, Dewdney J, Blee KA, Stone JM, Asai T, Plotnikov J, Denoux C, Hayes T, Gerrish C, Davies DR, et al: Peroxidase-dependent apoplastic oxidative burst in Arabidopsis required for pathogen resistance. Plant $J$ 2006, 47:851-863.

23. Chen YR, Deterding $L$, Sturgeon BE, Tomer KB, Mason RP: Protein oxidation of cytochrome $C$ by reactive halogen species enhances its peroxidase activity. J Biol Chem 2002, 277:29781-29791.

24. Valderrama B, Ayala M, Vazquez-Duhalt R: Suicide inactivation of peroxidases and the challenge of engineering more robust enzymes. Chem Biol 2002, 9:555-565.
25. Jankovic B, Seoighe C, Alqurashi M, Gehring C: Is there evidence of optimisation for carbon efficiency in plant proteomes? Plant Biol 2011 13:831-834

26. Ficarro SB, Parikh JR, Blank NC, Marto JA: Niobium(V) oxide (Nb2O5): application to phosphoproteomics. Anal Chem 2008, 80:4606-46131.

27. Kwon SJ, Kwon SI, Bae MS, Cho EJ, Park OK: Role of the methionine sulfoxide reductase MsrB3 in cold acclimation in Arabidopsis. Plant Cell Physiol 2007, 48:1713-1723.

doi:10.1186/1478-811X-11-1

Cite this article as: Marondedze et al:: Structural and functional characteristics of cGMP-dependent methionine oxidation in Arabidopsis thaliana proteins. Cell Communication and Signaling 2013 11:1.

\section{Submit your next manuscript to BioMed Central and take full advantage of:}

- Convenient online submission

- Thorough peer review

- No space constraints or color figure charges

- Immediate publication on acceptance

- Inclusion in PubMed, CAS, Scopus and Google Scholar

- Research which is freely available for redistribution

Submit your manuscript at www.biomedcentral.com/submit
C Biomed Central 